\title{
Variability of Findings in Drug-Induced Immune Haemolytic Anaemia: Experience over 20 Years in a Single Centre
}

\author{
Beate Mayer Thilo Bartolmäs Salih Yürek Abdulgabar Salama \\ Institute for Transfusion Medicine, Charité - Universitätsmedizin Berlin, Berlin, Germany
}

\section{Keywords \\ Drug-induced haemolysis - Anaemia - Drug-dependent antibodies · Ex vivo antigens · Complement · Intravascu- lar haemolysis - Fatal haemolysis}

\section{Summary}

Background: Drug-induced immune haemolytic anaemia (DIHA) is difficult to diagnose, and its true incidence remains obscure. Here, we present cases of DIHA identified at our institute over the last two decades. Methods: Serological tests were performed according to standard procedures. Detection of drug-dependent antibodies was performed in the presence and absence of the relevant drug and/or their ex vivo antigens. Results: Over the last 20 years, 73 patients have been identified with DIHA in our institute, which was related to 15 different drugs. The most common single drugs identified were diclofenac ( $n=23)$, piperacillin ( $n=13)$, ceftriaxone $(n=12)$ and oxaliplatin $(n=10)$. As far as data were available, haemolysis was acute in all patients, and signs of intravascular haemolysis were present in $90 \%$ of the cases. Haemolysis resulted in death in 17 patients $(23 \%)$. The remaining patients recovered, but haemolysis was complicated by transitory renal and/or liver failure or shock in 11 patients. Upon initial evaluation, the antibody screening test was positive in 36 cases. A positive direct antiglobulin test (DAT) at least with anti-C3d was found in 65 cases, with anti-lgG only in 6 cases, and with antilgA only in 1 case. Conclusion: DIHA is a rare but potentially life-threatening disorder that should be considered if a patient develops haemolysis under drug treatment. The main serological finding is a positive DAT, primarily with anti-C3d.

(C) 2015 S. Karger GmbH, Freiburg

\section{Introduction}

Drug-induced immune haemolytic anaemia (DIHA) is a rare complication of drug treatment and has an estimated incidence of approximately 1-4 cases per million individuals per year $[1,2]$. However, the true incidence is likely to be underestimated as there are a number of factors leading to misdiagnosis [3]. The disorder is usually characterised by the occurrence of abrupt immune haemolysis in association with drug administration. It is caused either by the production of drug-dependent antibodies (ddab) and/or, less commonly, autoantibodies (aab). The latter antibodies react with target cells in the presence, as well as in the absence, of the drug and cause Fc-mediated extravascular haemolysis. They are neither clinically nor serologically distinguishable from true aab. The former antibodies bind to red blood cells (RBCs) only in the presence of the sensitising drug, leading to predominantly complement-mediated intravascular haemolysis. In addition, some drugs are capable of stimulating the production of both types of antibodies [4].

Until now, more than 130 drugs have been reported to cause DIHA. Most commonly antibiotics, particularly the second and third generation cephalosporins, and platinum-based chemotherapies have been found to be the causative agents [5]. However, there is evidence that DIHA may frequently escape recognition, particularly if the causative drug has not been reported to cause immune haemolysis so far. Clinical signs and symptoms are variable, and serological results can be easily misinterpreted, e.g. as idiopathic autoimmune haemolytic anaemia (AIHA) or acute haemolytic transfusion reaction [6].

In this report, we describe new cases and present our findings of DIHA during the last two decades.

\section{Material and Methods}

All patients with confirmed DIHA during the last two decades in our institute were retrospectively reviewed. Clinical information and laboratory results

\section{KARGER \\ Fax +497614520714


Table 1. Drugs recognized to be responsible for immune haemolysis between 1996 and 2015 - clinically relevant data, complications and fatalities

\begin{tabular}{|c|c|c|c|c|c|c|c|c|c|}
\hline \multirow[t]{2}{*}{ Drug } & \multirow[t]{2}{*}{$\mathrm{n}$} & \multicolumn{2}{|c|}{$\operatorname{sex}$} & \multirow[t]{2}{*}{ Complications (n) } & \multicolumn{3}{|c|}{ Outcome } & \multirow[t]{2}{*}{ Published cases } & \multirow[t]{2}{*}{ Reference } \\
\hline & & $\mathrm{m}$ & $\mathrm{f}$ & & death & recovered & n.d. & & \\
\hline Diclofenac & 23 & 7 & 16 & $\begin{array}{l}\text { renal failure (4), } \\
\text { multi-organ failure (2), } \\
\text { circulatory failure (1) }\end{array}$ & 5 & 8 & 10 & 10 & {$[11,12]$} \\
\hline Piperacillin & 13 & 5 & 8 & $\begin{array}{l}\text { renal failure (2), } \\
\text { hypovolaemic shock (1) }\end{array}$ & 2 & 10 & 1 & 9 & {$[13]$} \\
\hline \multicolumn{10}{|l|}{ Cephalosporins } \\
\hline $\begin{array}{l}\text { Ceftriaxon } \\
\text { Cefotaxim }\end{array}$ & 12 & 4 & 8 & $\begin{array}{l}\text { renal failure (1), } \\
\text { multi-organ failure (2) } \\
\text { circulatory failure (1) } \\
\text { multi-organ failure (1) }\end{array}$ & 6 & 4 & 1 & 3 & {$[14,15]$} \\
\hline \multicolumn{10}{|c|}{ Platinum-based agents } \\
\hline Oxaliplatin & 10 & 3 & 7 & renal failure (3) & & 2 & 8 & 2 & {$[2]$} \\
\hline Carboplatin & 1 & & 1 & hepato-renal failure (1) & & & 1 & & \\
\hline Rifampicin & 4 & 2 & 2 & $\begin{array}{l}\text { renal failure ( } 2 \text { ) } \\
\text { heart and pulmonary failure (1) }\end{array}$ & 2 & 2 & & 3 & {$[16]$} \\
\hline \multicolumn{10}{|c|}{ Radiocontrast media } \\
\hline Iomeprol & 1 & & 1 & & & 1 & & 1 & {$[17]$} \\
\hline Iohexol & 1 & & 1 & liver failure (1) & & 1 & & & \\
\hline Etoricoxib & 1 & 1 & & & & 1 & & 1 & {$[18]$} \\
\hline $5-\mathrm{FU}$ & 1 & & 1 & circulatory failure (1) & 1 & & & 1 & [19] \\
\hline Ibuprofen & 1 & & 1 & & & & 1 & & \\
\hline Clindamycin & 1 & & 1 & & & 1 & & & \\
\hline Cotrimoxazol & 1 & & 1 & & & 1 & & & \\
\hline Total & 73 & 24 & 49 & & 17 & 32 & 24 & & \\
\hline
\end{tabular}

including haemoglobin levels, haemolysis, presenting symptoms and/or initial diagnosis, complications, and outcome, of the patients were included, if available. Blood samples from patients who developed haemolysis were referred to our laboratory for serological investigation or re-examination during or after the haemolytic attack.

$\mathrm{RBC}$ antibodies were tested by standard gel techniques with untreated and papain-treated group 0 RBCs using Liss/Coombs or buffered gel cards, respectively (DiaMed and subsequently Bio-Rad, Cressier sur Morat, Switzerland). The direct antiglobulin test (DAT) was performed using commercially available sera: anti-immunglobulin (Ig)G, anti-IgA, and anti-IgM (Biotest, Dreieich, Germany), and anti-C3d (Dako, Hamburg, Germany). Eluates from the patients' RBCs were performed by acid (Immucor, Rödermark, Germany) and on several occasions using the heat $\left(10 \mathrm{~min}, 56^{\circ} \mathrm{C}\right)$ technique [7].

ddab were investigated as previously described $[8,9]$. Briefly, drugs were dissolved in $0.9 \% \mathrm{NaCl}$ to prepare a $1 \mathrm{mg} / \mathrm{ml}$ solution. Patients' serum or plasma samples and, in selected cases, eluates from patients' RBCs $(25 \mu \mathrm{l})$ were incubated for $30 \mathrm{~min}$ at $37^{\circ} \mathrm{C}$ with group O RBCs $(50 \mu \mathrm{l}$ of a $1 \% \mathrm{vol} / \mathrm{vol}$ suspension) in the presence of the drug $(25 \mu \mathrm{l})$. Where possible, ex vivo antigens ( $50 \mu \mathrm{l}$ urine from patients under treatment with the drug) were additionally tested, particularly in cases demonstrating negative results with the native drug. In all cases, controls were included using saline instead of the drug (negative control 1), or serum samples from random donors instead of the patients' serum sam- ples (negative control 2). Serum samples that were found to be positive in the indirect antiglobulin test (IAT) prior to the addition of the drug solution, were dialyzed to eliminate possible residuals of the drug or its metabolites, followed by further analysis. If aab were detectable in dialyzed serum samples, these were incubated with group O RBCs to absorb the aab prior to testing for ddab [9].

Drug-coated RBCs were prepared as previously described [10] and used for the investigation of some piperacillin-dependent antibodies. The drug-coated $\mathrm{RBCs}$ were prepared by dissolving the drug in barbital buffer at $\mathrm{pH} 9.6$, followed by incubation of the drug solution with group $\mathrm{O}$ RBCs for $60 \mathrm{~min}$ at $37^{\circ} \mathrm{C}$.

\section{Results}

Between 1996 and 2015, we identified 73 patients with DIHA in our institute. Of these, 49 were females and 24 were males. The mean age of the patients was 63 years (range 16-92 years). ddab were found to be related to 15 different drugs (table 1). The most common drug involved was diclofenac, followed by piperacillin, ceftriaxone and oxaliplatin. 
Table 2. Cases

of dru-induced haemolysis - intravascular haemolysis, haemoglobin, suspected diagnosis

\begin{tabular}{|c|c|c|c|c|}
\hline Drug & $\mathrm{n}$ & $\begin{array}{l}\text { Intravascular } \\
\text { haemolysis* }\end{array}$ & Nadir $\mathrm{Hb}(\mathrm{g} / \mathrm{dl})^{*}$ & Initial diagnosis* \\
\hline Diclofenac & 23 & $\begin{array}{l}\text { y (9) } \\
\text { n.d. (14) }\end{array}$ & $\begin{array}{l}>8(5) \\
<8 \text { and } \geq 3(7) \\
<3(1) \\
\text { n.d. (10) }\end{array}$ & $\begin{array}{l}\text { AIHA (2) } \\
\text { confusion (2) } \\
\text { aortal aneurysm } \\
\text { transient ischaemic attack } \\
\text { mesenteric infarction / paralytic ileus } \\
\text { biliary obstruction (jaundice) } \\
\text { acute haemolytic transfusion reaction } \\
\text { haemolytic uremic syndrome } \\
\text { nephrotic syndrome }\end{array}$ \\
\hline Piperacillin & 13 & $\begin{array}{l}\text { y }(8) \\
\text { n (1) } \\
\text { n.d. (3) }\end{array}$ & $\begin{array}{l}>8(3) \\
<8 \text { and } \geq 3(8) \\
<3(1) \\
\text { n.d. (1) }\end{array}$ & \\
\hline \multicolumn{5}{|l|}{ Cephalosporins } \\
\hline Ceftriaxon & 12 & $\begin{array}{l}\text { y (9) } \\
\text { n.d. (3) }\end{array}$ & $\begin{array}{l}<8 \text { and } \geq 3(7) \\
<3(2) \\
\text { n.d. (3) }\end{array}$ & $\begin{array}{l}\text { AIHA (cold agglutinin disease) } \\
\text { bladder bleeding (haemoglobinuria) (2) } \\
\text { myocardial infarction } \\
\text { acute renal failure } \\
\text { confusion }\end{array}$ \\
\hline Cefotaxim & 2 & $y(2)$ & $\begin{array}{l}7.9(1) \\
\text { n.d. (1) }\end{array}$ & \\
\hline \multicolumn{5}{|c|}{ Platinum-based agents } \\
\hline Oxaliplatin & 10 & $\begin{array}{l}\text { y (2) } \\
\text { n.d. (8) }\end{array}$ & $\begin{array}{l}>8(1) \\
<8 \text { and } \geq 3(3) \\
\text { n.d. (6) }\end{array}$ & $\begin{array}{l}\text { AIHA (2) } \\
\text { acute renal failure } \\
\text { urinary tract infection (haemoglobinuria, fever) }\end{array}$ \\
\hline Carboplatin & 1 & $\mathrm{y}$ & 5.4 & \\
\hline Rifampicin & 4 & $\begin{array}{l}\text { y (2) } \\
\text { n.d. (2) }\end{array}$ & $<8$ and $\geq 3(4)$ & $\begin{array}{l}\text { AIHA (2) } \\
\text { pulmonary embolism } \\
\text { drug-induced hepatitis } \\
\text { acute haemolytic transfusion reaction }\end{array}$ \\
\hline \multicolumn{5}{|c|}{ Radiocontrast media } \\
\hline Iomeprol & 1 & $\mathrm{y}$ & 2.6 & allergic or toxic reaction \\
\hline Iohexol & 1 & $\mathrm{y}$ & 3.3 & AIHA (cold agglutinin disease), blood loss \\
\hline Etoricoxib & 1 & $\mathrm{n}$ & 8 & AIHA \\
\hline 5-FU & 1 & $\mathrm{y}$ & 8.4 & AIHA \\
\hline Ibuprofen & 1 & n.d. & n.d. & \\
\hline Clindamycin & 1 & $\mathrm{n}$ & 8 & \\
\hline Vancomycin & 1 & $\mathrm{n}$ & 8 & \\
\hline Cotrimoxazol & 1 & $\mathrm{y}$ & 7.5 & AIHA \\
\hline Total & 73 & & & \\
\hline $\begin{array}{l}\mathrm{y}=\text { Yes; } \mathrm{n}=\mathrm{no} \\
\text { or abdominal } \mathrm{p} \\
{ }^{*} \text { Number in bra }\end{array}$ & 它 & $\begin{array}{l}\text { ular haemoly } \\
\mathrm{U}=5 \text {-fluoro }\end{array}$ & aemoglobinuria & r haemoglobinaemia $(\mathrm{LDH}>1,000 \mathrm{U} / \mathrm{l})$, back an \\
\hline
\end{tabular}

The majority of patients presented with acute symptoms of severe anaemia. Potential associations with drugs were overlooked in numerous cases. The most common erroneous diagnosis was found to be AIHA of warm or cold type, which was suspected in 11 patients. In addition, various underlying diseases, including acute coronary symptoms, transient ischaemic attack, aortal aneurysm, mesenteric infarction, pulmonary embolism, hepatitis and biliary obstruction, were suspected. In at least 2 cases, DIHA was confused with an acute haemolytic transfusion reaction, and in another $2 \mathrm{pa}-$ tients haemoglobinuria was misinterpreted as acute bleeding of the bladder (table 2). 
Table 3. Serological findings in patients with DIHA

\begin{tabular}{|c|c|c|c|c|c|c|c|c|c|c|c|}
\hline \multirow[t]{2}{*}{ Drug } & \multirow[t]{2}{*}{$\mathrm{n}$} & \multicolumn{2}{|c|}{$\mathrm{DAT}^{*}$} & \multicolumn{3}{|c|}{ Eluate } & \multirow[t]{2}{*}{ IAT pos } & \multirow[t]{2}{*}{ Concomitant aab } & \multicolumn{3}{|c|}{$\mathrm{ddab}^{* *}$} \\
\hline & & IgG & C3d & pos & neg & n.t. & & & drug & ex vivo & drug / ex vivo \\
\hline Diclofenac & 23 & 19 & 17 & 17 & 4 & 2 & 16 & 18 & 1 & 10 & 12 \\
\hline Piperacillin & 13 & 13 & 11 & 4 & 9 & - & 5 & 2 & 3 & 2 & 8 \\
\hline \multicolumn{12}{|l|}{ Cephalosporins } \\
\hline Ceftriaxon & 12 & 10 & 12 & 1 & 9 & 2 & 3 & 2 & - & 2 & 11 \\
\hline Cefotaxim & 2 & - & 2 & - & 2 & - & 1 & - & - & 1 & 1 \\
\hline \multicolumn{12}{|c|}{ Platinum-based agents } \\
\hline Oxaliplatin & 10 & 10 & 8 & 5 & 4 & 1 & 0 & - & n.t. & n.t. & 10 \\
\hline Carboplatin & 1 & 1 & 1 & 1 & - & - & 1 & 1 & n.t. & n.t. & 1 \\
\hline Rifampicin & 4 & 4 & 4 & 1 & 3 & - & 4 & 2 & n.t. & n.t. $(2 / 4)$ & 4 \\
\hline \multicolumn{12}{|c|}{ Radiocontrast media } \\
\hline Iomeprol & 1 & - & 1 & 1 & - & - & 1 & 1 & n.t. & n.t. & 1 \\
\hline Iohexol & 1 & - & 1 & 1 & - & - & 1 & - & n.t. & n.t. & 1 \\
\hline Etoricoxib & 1 & 1 & 1 & - & 1 & - & 1 & - & - & - & 1 \\
\hline $5-\mathrm{FU}$ & 1 & 1 & 1 & - & 1 & - & 1 & 1 & - & 1 & - \\
\hline Ibuprofen & 1 & - & 1 & - & 1 & - & 0 & - & - & - & 1 \\
\hline Clindamycin & 1 & 1 & 1 & - & 1 & - & 1 & 1 & - & - & 1 \\
\hline Vancomycin & 1 & - & 1 & - & 1 & - & 1 & & n.t. & n.t. & 1 \\
\hline Cotrimoxazol & 1 & 1 & 1 & - & 1 & - & 0 & - & - & 1 & \\
\hline Total & 73 & & & 31 & 37 & 5 & 36 & 28 & & 17 & \\
\hline $\begin{array}{l}\text { n.t. }=\text { Not tested; } \\
{ }^{*} \text { DAT: } 1 \text { patient } \\
{ }^{*} \text { Drug: drug pos }\end{array}$ & $\begin{array}{l}\text { dru } \\
\text { ositi }\end{array}$ & $\begin{array}{l}\text { dif } \mathrm{t} \\
\text { AT; } \\
\text { ivo } \mathrm{pc}\end{array}$ & $\begin{array}{l}\text { d, ex } \\
\text { tient } \\
\text { ve on }\end{array}$ & posi & AT. & & the & positive & & & \\
\hline
\end{tabular}

A fatal outcome was observed in 17 patients (23\%); of these, 6 patients had ceftriaxone-dependent antibodies. 11 patients were found to temporarily develop severe complications such as renal and liver failure, but recovered following discontinuation of the drug and supportive treatment (table 1). Data concerning haemolysis were available from 42 patients, and $90 \%$ of these patients were observed to have acute and intravascular haemolysis. During the acute phase of haemolysis, the average minimum haemoglobin was $6.4 \mathrm{~g} / \mathrm{dl}$ (range $1.6-11 \mathrm{~g} / \mathrm{dl}$ ), but approximately $30 \%$ of the patients had a haemoglobin of or below $5 \mathrm{~g} / \mathrm{dl}$, and $10 \%$ of patients had a haemoglobin below $3 \mathrm{~g} / \mathrm{dl}$ (table 2).

The DAT was positive in 72 of the 73 patients. The remaining patient had been investigated 6 months after haemolysis. 65 patients $(89 \%)$ had a C3d-positive DAT ( $\pm \operatorname{IgG} \pm \operatorname{IgM} \pm \operatorname{IgA}), 6$ patients had only an IgG-positive DAT, and in 1 patient only IgA was detectable (table 3 ). The positivity of the DAT was found to vary considerably from weak positive (+/-) to very strong positive (4+).

In 36 (49\%) patients, serum was observed to positively react in the IAT with untreated RBCs without the addition of the drug. Dialysis of the serum resulted in completely negative reactions in 18 of the 36 patients, indicating that these serum samples contained the drug and/or its metabolites. In 28 (38\%) patients, reactivity of the samples was not or only partially decreased following serum dialysis, indicating that the reactions were related to drug-induced aab alone or in combination with ddab. Alloantibodies to RBCs were observed in 1 patient.

Eluates from the patients' RBCs were negative in 37 (54\%) of 68 cases analysed. Only 17 (23\%) of the 73 patients demonstrated a serological profile (IgG-positive and/or C3d-positive DAT, negative antibody-screening test and negative eluate) indicating the presence of DIHA rather than any other type of immune haemolysis. Typical serological characteristics consistent with warm reactive aab (IgG-positive DAT with or without C3d/IgM/IgA and a positive eluate) were observed in 27 (37\%) patients. In 3 cases, the serological picture during the haemolytic attack resembled cold agglutinin disease, with the presence of a C3d-only DAT and direct agglutinating antibodies in the serum without addition of the drug. The RBCs of one of these patients with iohexol-induced immune haemolysis also showed strong autoagglutination, possibly due to large amounts of the drug in the circulation.

ddab were detected in the patients' serum samples by IAT in all of the 73 patients. The serological pictures were variable and included weakly, strongly and directly agglutinating antibodies. As all of the serum samples were observed to react with RBCs in the 
presence of the drug and/or its metabolites, we only tested the serum of isolated cases against drug-coated RBCs (results not shown).

In 17 patients ( 10 diclofenac, 2 piperacillin, 2 ceftriaxone and 1 of each cefotaxim, 5-fluorouacil (5-FU), and cotrimoxazol), the causative antibodies required ex vivo antigens of the drug to demonstrate a reaction. In 4 patients, the ddab (3 piperacillin and 1 diclofenac) were only reactive in the presence of drug, but not with the drug metabolite. In the remaining cases, the antibodies were reactive in the presence of the causative drugs and their ex vivo antigens (table 3). The degree of positive reactivity in the presence of the drug or its metabolites was found to vary considerably from weak $(1+)$ to very strong $(4+)$.

Interestingly, we observed cross-reactivity between cephalosporins, e.g. ceftriaxon and cefotaxim. However, there was no evidence for the presence of ddab to different drugs in the same patient. The ddab of 7 patients were observed to demonstrate rhesus specificity: 4 patients' ddab reacted with e-positive RBCs (2 diclofenac, 2 piperacillin); and 3 patients' ddab (2 rifampicin, 1 diclofenac) reacted with C-positive RBCs.

\section{Discussion}

Due to the rare occurrence of DIHA, clinical and serological data are scarce. In this study, we report on our findings of cases identified in our institute during the last two decades.

There have been several reports addressing the incidence of certain drugs to cause DIHA; however, these data have not only changed dramatically during the last decades but have been found to vary between countries depending on a number of factors, including drug consumption [6]. In the 1970s, high-dose penicillin and methyldopa have been responsible for the majority of cases of DIHA, whereas in recent years, second- and third-generation cephalosporins have been most frequently reported $[2,5,20,21]$.

In the patient samples referred to our laboratory, diclofenac was, by far, the most common single drug associated with DIHA, followed by piperacillin, ceftriaxone and oxaliplatin. Altogether, these four drugs accounted for more than $80 \%$ of all cases of DIHA. This study is rather unique in the number of cases of diclofenacinduced IHA reported from one centre. The dominance of diclofenac-induced immune haemolytic anaemia (IHA) in our study most likely reflects the difference in the consumption of this drug in Europe compared with the USA; whereas diclofenac is one of the most highly prescribed drugs in Germany [22], it does not belong to the top 40 prescriptions in the USA [23]. Furthermore, due to concerns about vascular and gastrointestinal side effects, traditional non-steroidal anti-inflammatory drugs such as diclofenac are being increasingly replaced by newer drugs such as COX-2 selective drugs. Until now, only one case of DIHA due to COX-2 selective drugs has been reported [18].

The high rate of fatal outcomes in our study, which were particularly associated with ceftriaxone-induced IHA (6 of 12 cases), was rather striking. Taking into account previous reports, an acute and often fatal outcome is to be expected in patients with ceftriaxone-induced IHA [24-30]. Of the 26 cases of ceftriaxone-induced IHA reported by Garratty [6], a fatal haemolysis was observed in $36 \%$ of cases compared with $19 \%$ in cefotetan-induced IHA. Indeed, a fatal outcome has been more often reported to be associated with ceftriaxone than with any other drug associated with IHA, including other $\beta$-lactam antibiotics and diclofenac $[6,12]$. This may be related to the fact that ceftriaxone antibodies are primarily of IgM class [31]. Thus, the RBCs of the affected patients are almost invariably coated with C3d, and haemolysis is usually severe and intravascular, which was also observed to be the case in our study.

Of note, the second drug that was found to cause a comparable high rate of severe complications was rifampicin. Two of the 4 patients deceased, and 1 suffered from transient renal failure. At least 20 cases of rifampicin-induced haemolysis have been reported previously [32-38]. More than $60 \%$ of these patients had severe and intravascular hemolysis, and all but 1 patient developed acute renal failure.

We previously reported on the clinical and serological characteristics of 8 cases of piperacillin-induced IHA [13]. We found that 5 of our patients (63\%) and approximately $30 \%$ of the published cases with piperacillin-induced IHA had cystic fibrosis. Since then, several other reports of piperacillin-induced IHA in patients with cystic fibrosis have been published [39-45]. In the present study, we included 5 new cases of DIHA caused by piperacillin, and 2 of these patients were also found to be suffering from cystic fibrosis. Interestingly, 2 other patients had chronic obstructive pulmonary disease. It remains unclear whether patients with cystic fibrosis or other causes of chronic pulmonary infections may be susceptible in developing piperacillin-induced IHA, or if this phenomenon may solely be explained by the common use of piperacillin. Nonetheless, DIHA should be considered whenever these patients develop haemolysis following the administration of piperacillin.

Both the clinical and serological pictures of DIHA are variable, which may lead to false-negative results or misdiagnosis [3]. One of the major reasons for false-negative results is the number of ddab reacting with RBCs only in the presence of the drug metabolites, but not with the native drug. Trace metabolites as immunogenic agents have been described for different drugs in DIHA, such as buthiazide, nomifensine [46], 5-FU [47], anti-infective drugs [48], ceftriaxone [24] and some non-steroidal anti-inflammatory drugs $[21,49,50]$. In our study, 17 (23\%) of the ddab reacted only with ex vivo metabolites and would have been overlooked if analysis was performed only in the presence of the native drug. The rate of metabolite-dependent antibodies was particularly high amongst patients with diclofenac-induced IHA. Although it has been previously reported that the phenomenon of omitting drug metabolites from analysis may produce negative results $[49,51]$, it is of immense interest that approximately half of the diclofenac antibodies in our study were metabolite-dependent. Further metabolite-dependent antibodies were found in piperacillin-, ceftriaxone-, cefotaxim- and cotrimoxazol-induced IHA and, as expected, in 5-FUinduced IHA. Therefore, the use of ex vivo metabolites is manda- 
tory in cases of suspected DIHA and when a negative result is observed when testing in presence of the native drug. As drug metabolites are mostly unavailable or remain unknown, different ex vivo preparations, such as the patients' urine and urine or serum from other individuals taking the suspected drug, should be used to include rare or even private metabolites.

In cases where aab are detectable, a common misdiagnosis in DIHA is AIHA. In 46 (63\%) of all patients in this study, the serum or plasma was found to be reactive without the addition of the drug. In combination with an IgG-positive DAT and a positive eluate, which was observed in 29 patients, such findings may easily be misdiagnosed as idiopathic AIHA of the warm type, particularly if the causative antibodies demonstrate blood group specificity, such as auto-anti-e and auto-anti-C. In many cases, correct diagnosis could only be established after dialysis of the sample, which, in turn, decreased reactivity, and further analysis in the presence of the drug and/or its metabolites. In addition to the phenomenon that drugs may lead to the production of aab or ddab, some drugs also result in the production of both aab and ddab in the same patient [9]. Among the drugs investigated in our study, diclofenacdependent antibodies were most frequently associated with aab, which may or may not have been drug-induced. Thus, the presence of aab does not exclude ddab, and ddab should be suspected in all cases in which intravascular haemolysis abruptly develops. A C3dpositive DAT, with or without IgG, is a cardinal finding in all of these cases [52].
Another reason for serological misdiagnosis may be due to panagglutinating antibodies resembling cold agglutinins of high thermal amplitude or agglutinating IgM warm aab. They are quite characteristic in a number of cases during the acute phase of haemolysis, particularly when the drug and its metabolite are still present in the circulation [3]. Three of the ddab presented in this article demonstrated such a serological picture. Altogether, there are various pitfalls in the diagnosis and differential diagnosis of DIHA and AIHA, which have also been addressed in another article in this issue [53].

In summary, DIHA remains rather confounding in all aspects, including its pathogenesis and clinical and serological findings. These variabilities are not only observed for different drugs, but also for the same drug. Principally, any drug may induce IHA. This should be invariably suspected in all affected individuals under the treatment of drugs.

\section{Acknowledgement}

We thank Ramona Genth, Katrin Halle, Angela Herziger, Cornelia Knoth and Elena Puschkina for their expertise in performing the serological testing.

\section{Disclosure Statement}

The authors declare no conflicts of interest.

\section{References}

1 Petz L, Garratty G: Immune Hemolytic Anemias, 2nd ed. Philadelphia, Churchill Livingstone, 2004.

2 Garbe E, Andersohn F, Bronder E, Klimpel A, Thomae M, Schrezenmeier H, Hildebrandt M, Spath-Schwalbe E, Gruneisen A, Mayer B, Salama A, Kurtal H: Drug induced immune haemolytic anaemia in the berlin case-control surveillance study. Br J Haematol 2011; 154:644-653.

3 Salama A, Mayer B: Diagnostic pitfalls of drug-induced immune hemolytic anemia. Immunohematology 2014; 30:80-84.

4 Salama A: Drug-induced immune hemolytic anemia Exp Opin Drug Saf 2009;8:73-79.

5 Arndt PA: Drug-induced immune hemolytic anemia: THE last 30 years of changes. Immunohematology 2014;30:44-54.

6 Garratty G: Immune hemolytic anemia caused by drugs. Exp Opin Drug Saf 2012;11:635-642.

7 Mayer B, Yürek S, Kiesewetter H, Salama A: Mixedtype autoimmune hemolytic anemia: differential diagnosis and a critical review of reported cases. Transfusion 2008; 48:2229-2234.

8 Salama A, Berghofer H, Mueller-Eckhardt C: Detection of cell-drug (hapten)-antibody complexes by the gel test. Transfusion 1992;32:554-556.

-9 Salama A, Kroll H, Wittmann G, Mueller-Eckhardt C: Diclofenac-induced immune haemolytic anaemia: $\mathrm{Si}$ multaneous occurrence of red blood cell autoantibodies and drug-dependent antibodies. Br J Haematol 1996;95:640-644.
10 Petz L, Branch D: Drug-induced immune hemolytic anemia; in Chaplin HJ (ed): Immune Hemolytic Anemias. Edinburgh, Churchill Livingstone, 1985, pp 4794.

11 Ahrens N, Schewior L, Garbe E, Kiesewetter H, Salama A: Massive haemolysis after intramuscular diclofenac in a patient who apparently tolerated oral medication. Vox Sang 2004;86:71-74.

12 Ahrens N, Genth R, Kiesewetter H, Salama A: Misdiagnosis in patients with diclofenac-induced hemolysis: new cases and a concise review. Am J Hematol 2006; 81:128-131.

13 Mayer B, Yürek S, Salama A: Piperacillin-induced immune hemolysis: new cases and a concise review of the literature. Transfusion 2010;50:1135-1138.

14 Meyer O, Hackstein H, Hoppe B, Gobel FJ, Bein G, Salama A: Fatal immune haemolysis due to a degradation product of ceftriaxone. Br J Haematol 1999;105: 1084-1085.

15 Seltsam A, Salama A: Ceftriaxone-induced immune haemolysis: two case reports and a concise review of the literature. Intensive Care Med 2000;26:1390-1394.

16 Ahrens N, Genth R, Salama A: Belated diagnosis in three patients with rifampicin-induced immune haemolytic anaemia. Br J Haematol 2002;117:441-443.

17 Mayer B, Leo A, Herziger A, Houben P, Schemmer P, Salama A: Intravascular immune hemolysis caused by the contrast medium iomeprol. Transfusion 2013;53: 2141-2144.
18 Mayer B, Genth R, Dehner R, Salama A: The first example of a patient with etoricoxib-induced immune hemolytic anemia. Transfusion 2013;53:1033-1036.

19 Yürek S, Riess H, Kreher S, Dorken B, Salama A: Fatal immune haemolysis due to antibodies to individual metabolites of 5-fluorouracil. Transfus Med 2010;20: 265-268.

20 Garratty G: Immune hemolytic anemia associated with drug therapy. Blood Rev 2010;24:143-150.

21 Johnson ST, Fueger JT, Gottschall JL: One center's experience: the serology and drugs associated with druginduced immune hemolytic anemia - a new paradigm. Transfusion 2007;47:697-702.

22 Arzneiverordnungsreport 2012. Heidelberg, Springer, 2012

23 Lipton B, Laws C, Li L: Workers Compensation Prescription Drug Study: 2011 Update. National Council on Compensation Insurance Inc., 2011,

24 Garratty G, Postoway N, Schwellenbach J, McMahill PC: A fatal case of ceftriaxone (rocephin)-induced hemolytic anemia associated with intravascular immune hemolysis. Transfusion 1991;31:176-179.

25 Kakaiya R, Cseri J, Smith S, Silberman S, Rubinas TC, Hoffstadter A: A case of acute hemolysis after ceftriaxone: immune complex mechanism demonstrated by flow cytometry. Arch Pathology Lab Med 2004;128: 905-907. 
26 Bernini JC, Mustafa MM, Sutor LJ, Buchanan GR: Fatal hemolysis induced by ceftriaxone in a child with sickle cell anemia. J Pediatr 1995;126:813-815.

-27 Borgna-Pignatti C, Bezzi TM, Reverberi R: Fatal ceftriaxone-induced hemolysis in a child with acquired immunodeficiency syndrome. Pediatr Infect Dis J 1995; 14:1116-1117.

28 Tobian AA, Shirey RS, Savage WJ: Transfusion med illustrated: ceftriaxone-induced acute hemolytic anemia. Transfusion 2010;50:1647-1648

29 Dinesh D, Dugan N, Carter J: Intravascular haemolysis in a patient on ceftriaxone with demonstration of anticeftriaxone antibodies. Intern Med J 2008;38:438441.

30 Moallem HJ, Garratty G, Wakeham M, Dial S, Oligario A, Gondi A, Rao SP, Fikrig S: Ceftriaxone-related fatal hemolysis in an adolescent with perinatally acquired human immunodeficiency virus infection. J Pediatr 1998;133:279-281.

31 Arndt PA, Leger RM, Garratty G: Serologic characteristics of ceftriaxone antibodies in 25 patients with drug-induced immune hemolytic anemia. Transfusion 2012;52:602-612.

-32 Covic A, Goldsmith DJ, Segall L, Stoicescu C, Lungu S, Volovat C, Covic M: Rifampicin-induced acute renal failure: A series of 60 patients. Nephrol Dial Transplant 1998;13:924-929.

33 Govoni M, Moretti M, Menini C, Fiocchi F: Rifampicin-induced immune hemolytic anemia: Therapeutic relevance of plasma exchange. Vox Sang 1990; 59:246-247.

34 Pereira A, Sanz C, Cervantes F, Castillo R: Immune hemolytic anemia and renal failure associated with rifampicin-dependent antibodies with anti-i specificity AnnHematol 1991;63:56-58.

35 Tahan SR, Diamond JR, Blank JM, Horan RF: Acute hemolysis and renal failure with rifampicin-dependent antibodies after discontinuous administration. Transfusion 1985;25:124-127.
36 Manika K, Tasiopoulou K, Vlogiaris L, Lada M, Papaemmanouil S, Zarogoulidis K, Kioumis I: Rifampicinassociated acute renal failure and hemolysis: a rather uncommon but severe complication. Ren Fail 2013;35: 1179-1181.

37 Neunert CE, Paranjape GS, Cameron S, Rogers ZR: Intravascular hemolysis following low dose daily rifampin. Pediatr Blood Cancer 2008;51:821-823.

38 Dawe S, Lockwood DN, Creamer D: A case of postpartum borderline tuberculoid leprosy complicated by a median nerve abscess, peptic ulceration and rifampicin-induced haemolytic renal failure. Lepr Rev 2004;75:181-187.

39 Bandara M, Seder DB, Garratty G, Leger RM, Zuckerman JB: Piperacillin-induced immune hemolytic anemia in an adult with cystic fibrosis. Case Rep Med 2010;2010:161454.

40 Chavez A, Mian A, Scurlock AM, Blackall D, Com G: Antibiotic hypersensitivity in cf: drug-induced lifethreatening hemolytic anemia in a pediatric patient. J Cyst Fibros 2010;9:433-438.

41 Arndt PA, Leger RM, Garratty G: Serological characteristics of anti-piperacillin in seventeen patients with drug-induced immune hemolytic anemia. Transfusion 2010;50:37A

42 Pierce A, Nester T; Education Committee of the Academy of Clinical Laboratory Physicians and Scientists.: Pathology consultation on drug-induced hemolytic anemia. AmJ Clin Pathol 2011;136:7-12.

43 Marik PE, Parekh P: Life-threatening piperacillin-induced immune haemolysis in a patient with cystic fibrosis. BMJ Case Rep 2013;2013

44 Nagao B, Yuan S, Bon Homme M: Sudden onset of severe anemia in a patient with cystic fibrosis. Clin Chem 2012;58:1286-1289.
45 Gehrie E, Neff AT, Ciombor KK, Harris N, Seegmiller AC, Young PP: Transfusion medicine illustrated. Profound piperacillin-mediated drug-induced immune hemolysis in a patient with cystic fibrosis. Transfusion 2012;52:4-5.

46 Salama A, Mueller-Eckhardt C, Kissel K, Pralle H, Seeger W: Ex vivo antigen preparation for the serological detection of drug-dependent antibodies in immune haemolytic anaemias. Br J Haematol 1984;58:525-531.

47 Sandvei P, Nordhagen R, Michaelsen TE, Wolthuis K: Fluorouracil (5-FU) induced acute immune haemolytic anaemia. Br J Haematol 1987;65:357-359.

48 Salama A, Burger M, Mueller-Eckhardt C: Acute immune hemolysis induced by a degradation product of amphotericin B. Blut 1989;58:59-61.

49 Johnson ST, Weitekamp LA, Wilkins JL, Heim ED, MacDonald JD, Barylak EJ: Diclofenac-dependent antibody with relative e specificity causing hemolytic anemia and emphasizing the need for metabolite testing. Transfusion 1993;33(suppl):63S.

50 Cunha PD, Lord RS, Johnson ST, Wilker PR, Aster $\mathrm{RH}$, Bougie DW: Immune hemolytic anemia caused by sensitivity to a metabolite of etodolac, a nonsteroidal anti-inflammatory drug. Transfusion 2000;40:663-668.

51 Sachs UJ, Santoso S, Roder L, Smart E, Bein G, Kroll H: Diclofenac-induced antibodies against red blood cells are heterogeneous and recognize different epitopes. Transfusion 2004;44:1226-1230.

52 Salama A: Drug-induced immune hemolytic anemia; in Sipes IG, McQuenn CA, Gandolfi AJ (eds): Comprehensive Toxicology. New York, Elsevier, 1997, vol 4, pp 73-85.

53 Salama A: Clinically and/or serologically misleading findings in autoimmune haemolytic anaemias. Transfus Med Hemother 2015;42: DOI: 10.1159/000438960. 